\title{
Deficiency of Src homology 2 domain- containing inositol 5-phosphatase 1 affects platelet responses and thrombus growth
}

Sonia Séverin, ${ }^{1}$ Marie-Pierre Gratacap, ${ }^{1}$ Nadège Lenain, ${ }^{2}$ Laetitia Alvarez, ${ }^{3}$ Etienne Hollande, ${ }^{3}$ Josef M. Penninger, ${ }^{4}$ Christian Gachet, ${ }^{2}$ Monique Plantavid, ${ }^{1}$ and Bernard Payrastre ${ }^{1}$

${ }^{1}$ INSERM U 563, Centre de Physiopathologie de Toulouse Purpan et Université Paul Sabatier, Département d' Oncogenèse et Signalisation dans les Cellules Hématopoïétiques, Toulouse, France. 2INSERM U 311,

Etablissement Français du Sang-Alsace, Strasbourg, France. ${ }^{3}$ Laboratoire de Biologie Cellulaire et Moléculaire des Epithéliums, Université Paul Sabatier, Toulouse, France. ${ }^{4}$ Institute of Molecular Biotechnology of the Austrian Academy of Sciences, Vienna, Austria.

\begin{abstract}
Platelets are critical for normal hemostasis. Their deregulation can lead to bleeding or to arterial thrombosis, a primary cause of heart attack and ischemic stroke. Src homology 2 domain-containing inositol 5-phosphatase 1 (SHIP1) is a 5-phosphatase capable of dephosphorylating the phosphatidylinositol 3,4,5-trisphosphate second messenger into phosphatidylinositol 3,4-bisphosphate. SHIP1 plays a critical role in regulating the level of these 2 lipids in platelets. Using SHIP1-deficient mice, we found that its loss affects platelet aggregation in response to several agonists with minor effects on fibrinogen binding and $\beta_{3}$ integrin tyrosine phosphorylation. Accordingly, SHIP1-null mice showed defects in arterial thrombus formation in response to a localized laser-induced injury. Moreover, these mice had a prolonged tail bleeding time. Upon stimulation, SHIP1deficient platelets showed large membrane extensions, abnormalities in the open canalicular system, and a dramatic decrease in close cell-cell contacts. Interestingly, SHIP1 appeared to be required for platelet contractility, thrombus organization, and fibrin clot retraction. These data indicate that SHIP1 is an important element of the platelet signaling machinery to support normal hemostasis. To our knowledge, this is the first report unraveling an important function of SHIP1 in the activation of hematopoietic cells, in contrast to its well-documented role in the negative regulation of lymphocytes.
\end{abstract}

\section{Introduction}

Platelet activation is a highly regulated process and critical for mediating normal hemostasis. Vascular injury exposes subendothelial matrix proteins that allow platelet arrest and their subsequent spreading, activation, and secretion of soluble mediators. These soluble agonists recruit circulating platelets, allowing aggregation for the bleeding to stop. In pathological states, platelet activation can contribute to thrombosis and cerebrovascular and arterial occlusion and eventually to heart attacks and strokes. Several signaling mechanisms have been shown to contribute to platelet activation, including the phospholipase $\mathrm{C}(\mathrm{PLC}) / \mathrm{Ca}^{2+}$ and the PI3K pathways. By generating phosphatidylinositol 3,4,5-trisphosphate $\left[\operatorname{PtdIns}(3,4,5) \mathrm{P}_{3}\right]$ and phosphatidylinositol 3,4-bisphosphate $\left[\operatorname{PtdIns}(3,4) \mathrm{P}_{2}\right]$ second messengers, PI3K plays an important role in platelet activation and plug stability (1-3). Using a selective PI3K $\beta$ inhibitor, Jackson et al. (3) recently suggested that this lipid kinase could be a potential target for antithrombotic therapy.

It is now well established in several models that phosphoinositide phosphatases involved in the hydrolysis of $\operatorname{PtdIns}(3,4,5) \mathrm{P}_{3}$ and PtdIns $(3,4) \mathrm{P}_{2}$, such as the phosphatase and tensin homolog (PTEN), are essential for the negative regulation of PI3K pathways (4). PTEN is commonly deleted or inactivated in several cancers,

Nonstandard abbreviations used: MLC, myosin light chain; OCS, open canalicular system; PH, pleckstrin homology; PLC, phospholipase C; PRP, platelet-rich plasma; PtdIns $(3,4) \mathrm{P}_{2}$, phosphatidylinositol 3,4-bisphosphate; PtdIns $(3,4,5) \mathrm{P}_{3}$, phosphatidylinositol 3,4,5-trisphosphate; PTEN, phosphatase and tensin homolog; SHIP, Src homology 2 domain-containing inositol 5-phosphatase.

Conflict of interest: The authors have declared that no conflict of interest exists. Citation for this article: J. Clin. Invest. 117:944-952 (2007). doi:10.1172/JCI29967. leading to the overactivation of PI3K signaling. The contribution of the different phosphoinositide phosphatases to platelet regulation is still poorly characterized. Src homology 2 domain-containing inositol 5-phosphatase 1 (SHIP1) plays a critical role in the control of PtdIns $(3,4,5) \mathrm{P}_{3}$ and PtdIns $(3,4) \mathrm{P}_{2}$ levels, but its implication in the regulation of platelet functions remains largely unknown. SHIP1 and SHIP2 form a subgroup of the inositol polyphosphate 5-phosphatase family acting as negative regulators of several signal transduction pathways downstream of PI3K, including Akt activation $(5,6)$. SHIP1 is expressed in hematopoietic cells, whereas SHIP2 is ubiquitous. Both proteins share a high degree of identity, and, besides a central 5-phosphoinositol phosphatase domain, they contain multiple protein-protein interaction domains, including an $\mathrm{N}$-terminal Src homology 2 domain, a C-terminal proline-rich region, and 2 phosphotyrosine-binding consensus sequences (i.e., NPxY sequences; ref. 7).

SHIP1-deficient mice show an increased number of myeloid progenitors in their bone marrow and spleen, and these progenitors display enhanced responsiveness to cytokines. They develop marked pulmonary infiltrates of hyperproliferative macrophages and granulocytes. The platelet count of SHIP1-deficient mice is not affected $(8,9)$.

SHIP1 becomes tyrosine-phosphorylated upon thrombin stimulation in an aggregation- and $\alpha_{\mathrm{IIb}} \beta_{3}$ integrin engagement-dependent manner (10), leading to the generation of new potential docking sites for signaling proteins. Loss of SHIP1 expression is sufficient to induce an accumulation of $\operatorname{PtdIns}(3,4,5) \mathrm{P}_{3}$ and a strong decrease in $\operatorname{PtdIns}(3,4) \mathrm{P}_{2}$ production in platelets stimulated by thrombin or collagen (11). Recent studies suggest a role for 
A

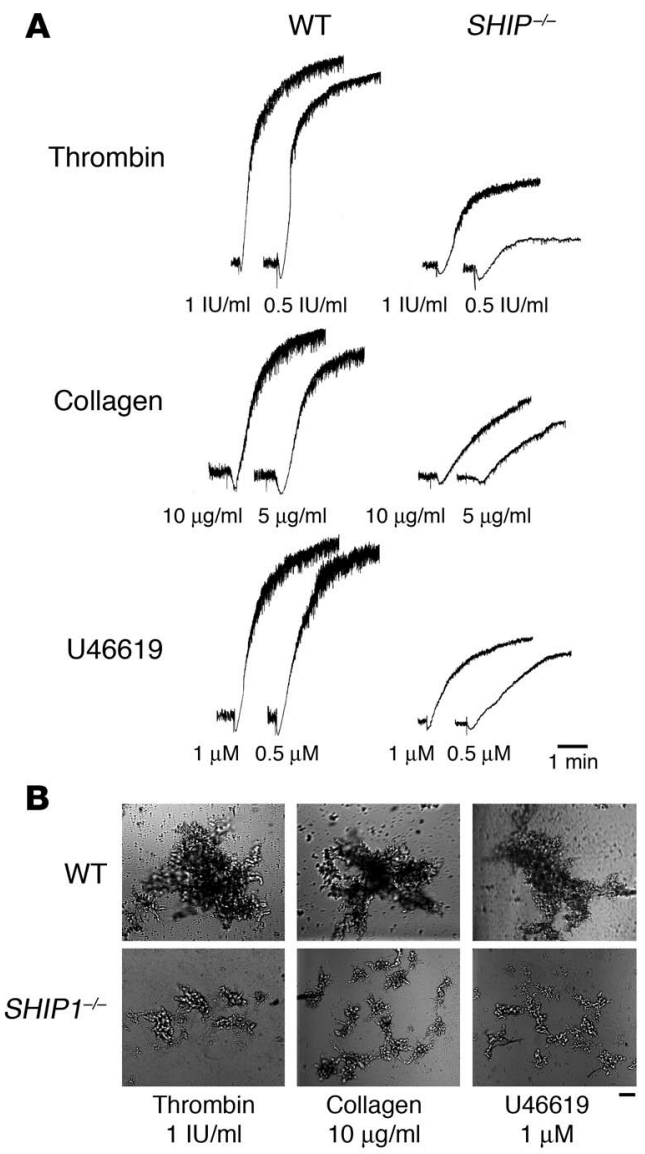

SHIP1 in the control of calcium entry (12) and in $\alpha_{\mathrm{IIb}} \beta_{3}$-induced signaling in platelets adhered on a fibrinogen-coated surface (13). To gain insight into the function of this protein, we investigated in detail the phenotype of SHIP1-deficient platelets in vitro and in vivo. Using mice bearing a targeted disruption of both SHIP1 alleles (14), we demonstrate that this phosphatase is important for primary hemostasis as shown by increased tail bleeding time. Accordingly, platelet aggregation and thrombus growth were affected in vitro and in vivo. SHIP1 deficiency led to a dramatic defect in the platelet contractile apparatus, leading to a decrease in close cell-cell contacts and an inhibition of fibrin clot retraction. Our results show that SHIP1 is an important protein of the platelet signal transduction process that leads to a normal hemostasis.

\section{Results}

Impaired in vitro aggregation of SHIP1-deficient platelets. To determine whether SHIP1 is involved in the signaling mechanisms supporting platelet aggregation, SHIP1-deficient platelets and platelets from normal littermates were stimulated by different concentrations of thrombin, collagen, or the thromboxane $\mathrm{A}_{2}$ analogue U46619 (Figure 1A). Platelets from SHIP1-deficient mice showed a marked defect in aggregation in response to these agonists. Raising the agonist concentration increased aggregation but did not restore a normal response. As shown by differential interference contrast, SHIP1-deficient platelets stimulated by $1 \mathrm{IU} / \mathrm{ml}$ thrombin, $10 \mu \mathrm{g} / \mathrm{ml}$ collagen, or $1 \mu \mathrm{M}$ U46619 formed microaggregates (Figure 1B). These microaggregates were stable and did not disaggregate with time (not shown). No apparent defect in platelet-

\section{Figure 1}

Aggregation defects in SHIP1-deficient platelets. (A) Platelets were stimulated with thrombin, collagen, and the thromboxane $A_{2}$ analogue U46619, and aggregation was assessed with a Chrono-log dual-channel aggregometer under stirring at $900 \mathrm{rpm}$ for 5 minutes. The profiles shown are representative of 5 independent experiments. (B) Platelets were then fixed with $1.5 \%$ paraformaldehyde for 30 minutes at room temperature, and observed by differential interference contrast with the use of a Nikon Eclipse TE $2000-U$ equipped with a $\times 10$ objective and a DXM 1200 digital camera (scale bar: $40 \mu \mathrm{m}$ ). Data shown are representative of 3 independent experiments.

shape change could be observed in response to the different agonists tested. Thus, SHIP1 appears to regulate the size of platelet aggregates in response to various agonists in vitro.

Dynamics of thrombus formation under flow. To further investigate this functional defect, we examined thrombus formation under physiological flow conditions. Fluorescently labeled platelets in whole blood were perfused over a matrix of collagen at a shear rate of $1,500 \mathrm{~s}^{-1}$ (15 dynes $\left./ \mathrm{cm}^{2}\right)$ during 2 minutes. Blood from control mice exhibited robust formation of densely packed platelets on collagen (Figure 2, A and B). In marked contrast, SHIP1-deficient platelets attached along the length of the collagen fibers but formed smaller thrombi (Figure 2, A and B). As shown in Figure 2 , $C$ and $D$, the surface covered by platelet aggregates $(13 \% \pm 2.9 \%$ for SHIP1-deficient platelets versus $28.7 \% \pm 2.5 \%$ for WT platelets) and the thrombus volume $\left(0.6 \times 10^{5} \pm 0.2 \times 10^{5} \mu \mathrm{m}^{3}\right.$ for SHIP1deficient platelets versus $1.6 \times 10^{5} \pm 0.1 \times 10^{5} \mu \mathrm{m}^{3}$ for WT platelets) were significantly reduced.

These results indicate that under physiological shear rate conditions, SHIP1-deficient platelets formed smaller aggregates on the collagen fibers as compared with control platelets (Figure 2B).

SHIP1-deficient platelets exhibit defects in dense-granule and $\alpha$-granule secretion. To check whether this platelet aggregation defect was due to a lack of secretion of dense or $\alpha$-granules, we analyzed the secretion of serotonin (Table 1 ) and the expression of P-selectin (Figure 3 and Table 2). The basal level of P-selectin expression was comparable in WT and SHIP1-deficient platelets (Figure 3 and Table 2). Upon platelet stimulation by different doses of thrombin, the absence of SHIP1 induced a moderate (about 20\%) inhibition of the secretion of dense or $\alpha$-granules. In the case of $10 \mu \mathrm{g} / \mathrm{ml} \mathrm{col-}$

\section{Table 1}

Defects in dense-granule secretion in SHIP1-deficient platelets

\begin{tabular}{lcc}
\hline & \multicolumn{2}{c}{$\begin{array}{c}\text { Percentage of 5-hydroxy[14C]tryptamine } \\
\text { secretion in response to various agonists }\end{array}$} \\
Agonist & WT mice & SHIP1-/- mice \\
Resting & $15 \pm 2$ & $15 \pm 1.5$ \\
Thrombin $(0.1 \mathrm{IU} / \mathrm{ml})$ & $57 \pm 6$ & $37 \pm 10.5$ \\
Thrombin $(0.5 \mathrm{IU} / \mathrm{ml})$ & $81 \pm 3$ & $63.5 \pm 6^{\mathrm{A}}$ \\
Thrombin $(1 \mathrm{IU} / \mathrm{ml})$ & $86 \pm 3$ & $68 \pm 5.5^{\mathrm{A}}$ \\
Collagen $(10 \mu \mathrm{g} / \mathrm{ml})$ & $44 \pm 8$ & $45 \pm 6$ \\
U46619 $(5 \mu \mathrm{M})$ & $46.5 \pm 3$ & $28 \pm 7^{\mathrm{A}}$
\end{tabular}

Dense-granule secretion was analyzed in WT and SHIP1-deficient mice platelets previously labeled with 5 -hydroxy $\left[{ }^{14} \mathrm{C}\right]$ tryptamine under resting or stimulated conditions as indicated. Values are means \pm SEM of 5 independent determinations. ASignificant difference $(P<0.05)$ versus WT, according to 1-tailed Student's $t$ test. 
A Time (s)

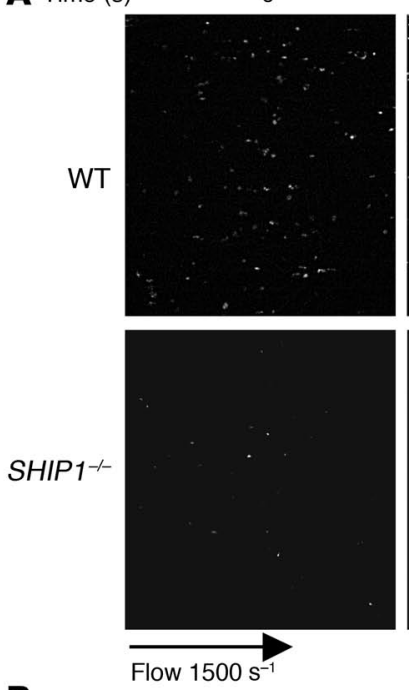

$\mathbf{B}$

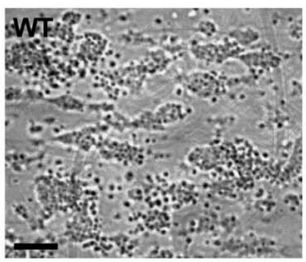

30
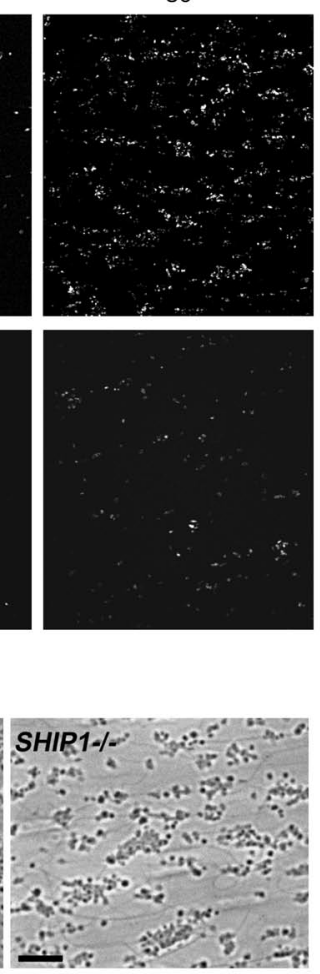
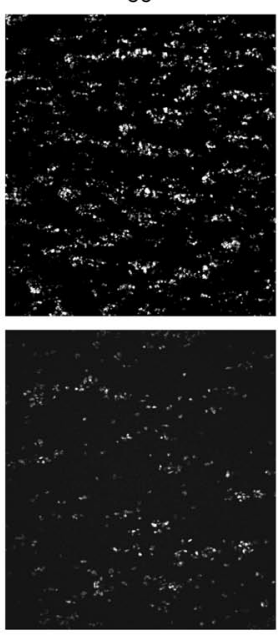

C

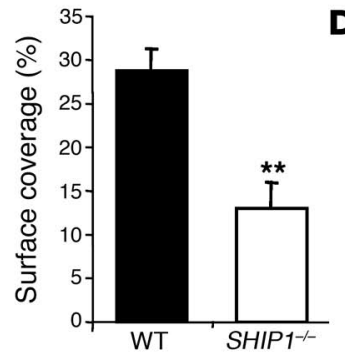

90
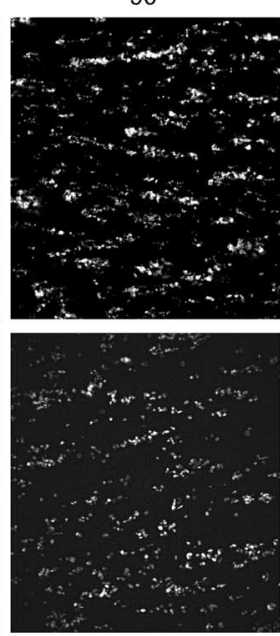
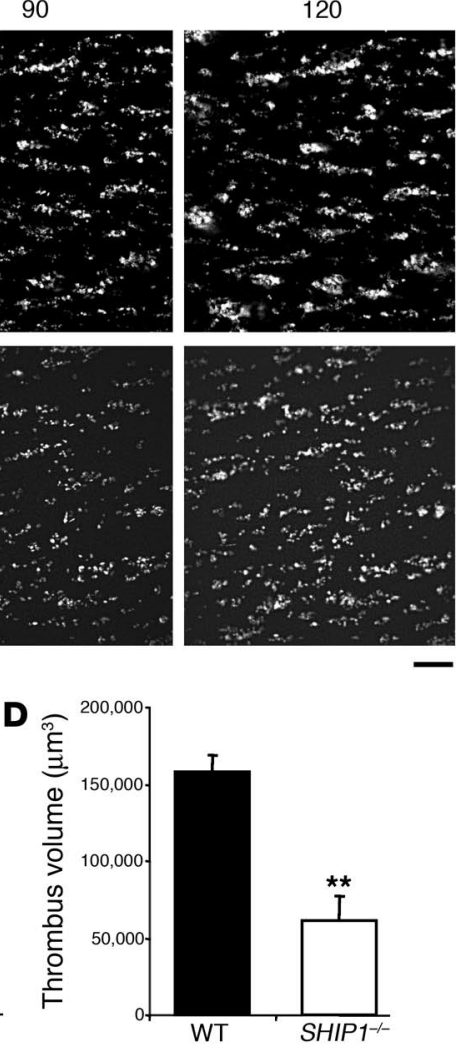

\section{Figure 2}

Thrombus formation defect in SHIP1-deficient platelets under arterial flow conditions. DiOC 6 -labeled platelets in whole blood were perfused through a collagen-coated microcapillary at a shear rate of $1,500 \mathrm{~s}^{-1}$ during 2 minutes. (A) Thrombus formation was visualized with a $\times 40$ longworking-distance objective in real time and then imaged by transmitted light microscopy (B) (scale bar: 20 um). (C and D) Area covered by platelet thrombi $(\mathbf{C})$ and thrombus volume (D) were measured at 2 surface locations in each of 3 different experiments (mean \pm SEM). ${ }^{*}$ Significant difference $(P<0.005)$ versus WT, according to 1 -tailed Student's $t$ test.

lagen stimulation, which induced a weak secretion in comparison with high doses of thrombin, absence of SHIP1 had only a minor effect on the degranulation response. Finally, platelet secretion induced by $5 \mu \mathrm{M}$ U46619 was markedly inhibited (about 40\%) in SHIP1-deficient platelets. These results indicate that there is only a partial involvement of SHIP1 in degranulation that cannot totally explain the aggregation defect of SHIP1-deficient platelets.

We then checked whether cytosolic calcium response would be disturbed in the absence of SHIP1 (Supplemental Figure 1; supplemental material available online with this article; doi: $10.1172 /$ JCI29967DS1). The basal cytosolic calcium level was comparable in SHIP1-deficient platelets and in control platelets. Moreover, the calcium mobilization and the overall pattern of cytosolic calcium flux in response to thrombin, collagen, or U46619 were normal in SHIP1deficient platelets (Supplemental Figure 1, A-C). In agreement, the production of phosphatidic acid, which reflects PLC activation in platelets (15), was only slightly affected in SHIP1-deficient platelets stimulated by these agonists as compared with WT (not shown).

Role of SHIP1 in the formation of compacted platelet aggregates. To further characterize the defect in platelet aggregation, we investigated the ultrastructure of SHIP1-deficient platelets by electron microscopy (Figure 4A). Under resting conditions, platelet size and volume, dispersion of $\alpha$-granules and dense bodies, and the organization of the open canalicular system (OCS) were comparable in WT and SHIP1-deficient platelets (not shown). As expected, upon thrombin stimulation, WT platelets formed close contacts and underwent degranulation. By contrast, in SHIP1-deficient platelets, thrombin stimulation caused the distension of the internal membrane system (dilated portions of the OCS), which was accompanied by the appearance of large vacuoles (Figure 4A, black arrows) and a few randomly dispersed granules. SHIP1-deficient platelets formed some membrane extensions (Figure 4A, white arrows) but exhibited decreased cell-cell contacts in response to thrombin. The close proximity of the plasma membranes of adjacent WT platelets was no longer observed in SHIP1-deficient platelets. These morphological differences correlated with an increase in the apparent surface occupied by the central body of SHIP1deficient platelets stimulated by thrombin as compared with WT platelets (surface increase: $103 \% \pm 8 \%, n=20$ ), suggesting a lower contractility. These data show that SHIP1 plays a critical role in the formation of densely compacted platelet aggregates.

Fibrinogen binding and $\beta_{3}$ integrin phosphorylation in SHIP1-deficient platelets. Fibrinogen binding is critical for platelet aggregation and is a reflection of $\alpha_{\mathrm{II}} \beta_{3}$ integrin activation, a process that depends on inside-out signaling. To evaluate the role of SHIP1 in $\alpha_{\mathrm{IIb}} \beta_{3}$ integrin activation, we analyzed fibrinogen binding to platelets from WT and SHIP1-deficient mice. Interestingly, SHIP1-deficient platelets bound comparable amounts of Oregon Green 488-conjugated 

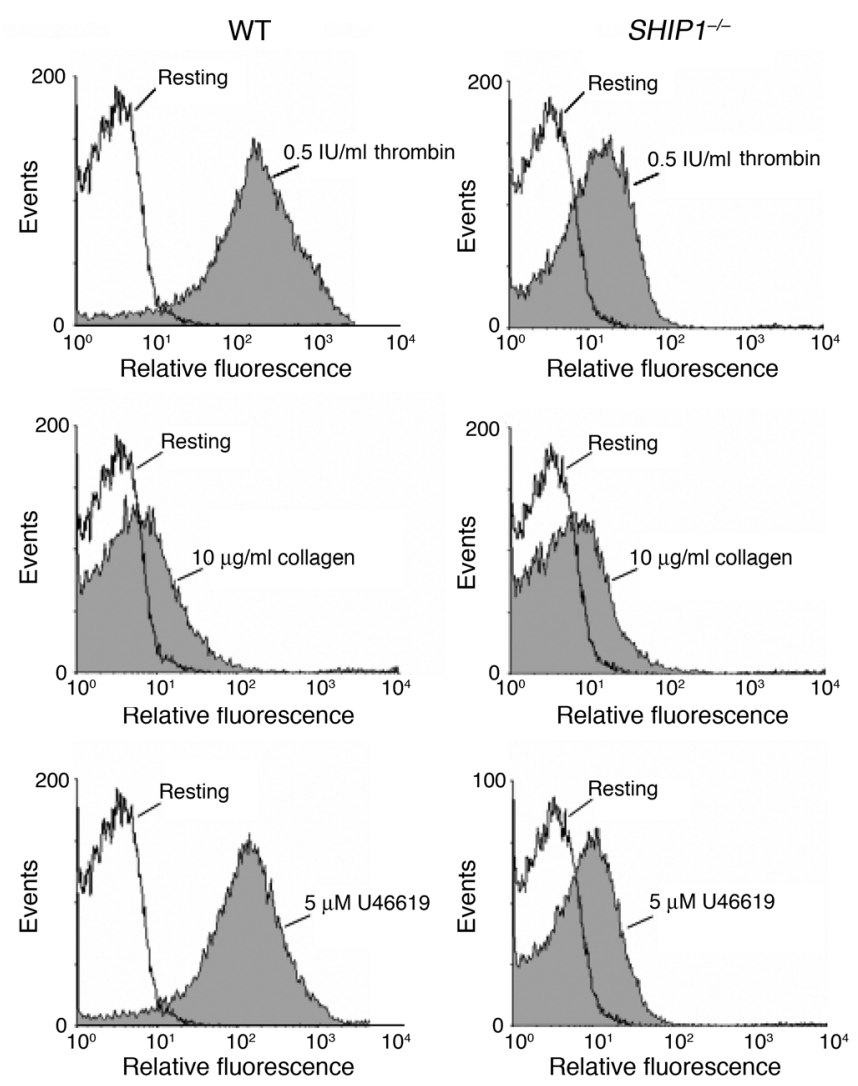

Figure 3

P-selectin expression defects in SHIP1-deficient platelets. P-selectin expression was analyzed by flow cytometry in WT and SHIP1-deficient mice platelets under resting (white) or stimulated (gray) conditions as indicated.

fibrinogen in response to increasing concentrations of thrombin or U46619 (Figure 4B), indicating that $\alpha_{\mathrm{II}} \beta_{3}$ inside-out signaling was not significantly affected by the absence of SHIP1. Upon ligand binding, critical tyrosine residues in the cytoplasmic tail of the $\beta_{3}$ integrin become phosphorylated and serve as docking sites for downstream signaling molecules (16). We therefore assessed the role of SHIP1 in $\beta_{3}$ integrin tyrosine phosphorylation under conditions in which no exogenous fibrinogen was added. As shown by immunoblotting using an anti- $\beta_{3}$ integrin [ $\left.\mathrm{pY}^{773}\right]$ phosphospecific antibody (Figure 4C), at low doses of thrombin $(<0.1 \mathrm{IU} / \mathrm{ml})$, the absence of SHIP 1 affected $\beta_{3}$ phosphorylation (28\% decrease, $P<0.05)$. Raising the agonist concentration did overcome the defect, as the $\beta_{3}$ integrin tyrosine phosphorylation was normal at higher doses of thrombin $(>0.1 \mathrm{IU} / \mathrm{ml})$. These results indicate that SHIP1 is dispensable for $\alpha_{\mathrm{IIb}} \beta_{3}$ inside-out signaling but is involved in $\alpha_{\mathrm{IIb}} \beta_{3}$ outside-in signaling at low doses of agonist.

Mice lacking SHIP1 have increased bleeding time and form smaller thrombi in vivo. To assess whether the altered responsiveness of SHIP1-deficient platelets in vitro would correlate with plateletdependent primary hemostasis defects in vivo, we evaluated bleeding time. In WT mice, bleeding induced by amputation of the tail tip was controlled within 2-3 minutes, whereas SHIP1-deficient mice kept bleeding (Figure 5A).

To determine whether this bleeding diathesis correlated with a defect in thrombus formation in vivo, we studied the behavior of SHIP1-deficient platelets in a model of arterial thrombus formation by intravital microscopy of the locally injured mesenteric arteries (17). After induction of a superficial injury of the mesenteric arteries using a laser, WT platelets rapidly adhered to the site of endothelial desquamation and formed a thrombus (Figure 5B). Platelets lacking SHIP1 also adhered rapidly to the injured vessel wall as shown by the curve inclination, which was similar in WT and SHIP1-deficient platelets. However, consistent with the data obtained in vitro, the thrombus size and the total number of platelets that composed the thrombus were significantly reduced in SHIP1-null mice compared with WT mice (Figure 5B). The subsequent progressive appearance and disappearance of the thrombus were comparable in both mouse models. These results indicate that the initial adhesion of platelets to the injured vessel wall is not altered. However, SHIP1 is involved in platelet thrombus growth in vivo.

Defect in thrombus organization in mice lacking SHIP1. When a high concentration of collagen $(0.4 \mathrm{mg} / \mathrm{kg})$ and epinephrine $(60 \mu \mathrm{g} / \mathrm{kg})$ was injected into the jugular vein, SHIP1-deficient mice were not protected against thromboembolism (not shown). However, histological analysis of mouse lungs harvested 3 minutes after a nonlethal i.v. injection of a lower dose of collagen $(0.15 \mathrm{mg} / \mathrm{kg})$ in association with epinephrine $(60 \mu \mathrm{g} / \mathrm{kg})$ showed marked differences in the occlusive thrombi in vessels from WT mice compared with SHIP1-deficient mice (Figure 6A). WT mouse thrombi were rich in platelets and well organized. In contrast, the pulmonary thrombi formed in SHIP1-deficient mice contained less platelet as shown by the $\alpha_{\text {IIb }}$ integrin staining intensity (Figure 6B). These results are in agreement with the microaggregates observed in vitro (Figures 1 and 2) and the decreased thrombus size measured in vivo upon vessel injury (Figure 5). Thus, SHIP1 is required for normal platelet aggregate formation and is involved in thrombus organization in vivo.

Defect in myosin light chain phosphorylation and clot retraction in SHIP1deficient platelets. Overall, the phenotype of SHIP1-deficient platelets suggests a defect in the contractile apparatus. Therefore, we investigated myosin light chain (MLC) phosphorylation, which is required for efficient actomyosin formation and contractility. In order to avoid the $\alpha_{\mathrm{II}} \beta_{3}$ integrin- and aggregation-dependent MLC phosphorylation, the experiment was performed in the presence of the $\alpha_{\mathrm{IIb}} \beta_{3}$ integrin antagonist SR-121566A (18). In WT and SHIP1deficient platelets, maximal MLC phosphorylation was observed 10 seconds after thrombin addition, but the phosphorylation intensity was dramatically decreased in SHIP1-deficient platelets

\section{Table 2}

P-selectin expression in response to various agonists (percentage P-selectin-positive platelets)

\begin{tabular}{lcc}
\hline & WT mice & SHIP1-- mice \\
Resting & $14 \pm 1$ & $15 \pm 1$ \\
Thrombin $(0.1 \mathrm{IU} / \mathrm{ml})$ & $40 \pm 11$ & $30 \pm 12$ \\
Thrombin $(0.5 \mathrm{IU} / \mathrm{ml})$ & $78 \pm 4$ & $56 \pm 5^{\mathrm{A}}$ \\
Thrombin $(1 \mathrm{IU} / \mathrm{ml})$ & $82.5 \pm 2$ & $65 \pm 6^{\mathrm{B}}$ \\
Collagen $(10 \mu \mathrm{g} / \mathrm{ml})$ & $32 \pm 5$ & $25 \pm 2$ \\
U46619 $(5 \mu \mathrm{M})$ & $78.5 \pm 3$ & $44 \pm 10^{\mathrm{A}}$
\end{tabular}

Values are means \pm SEM of 5 independent determinations. ASignificant difference $(P<0.005)$. BSignificant difference $(P<0.05)$ versus WT, according to 1-tailed Student's $t$ test. 
A
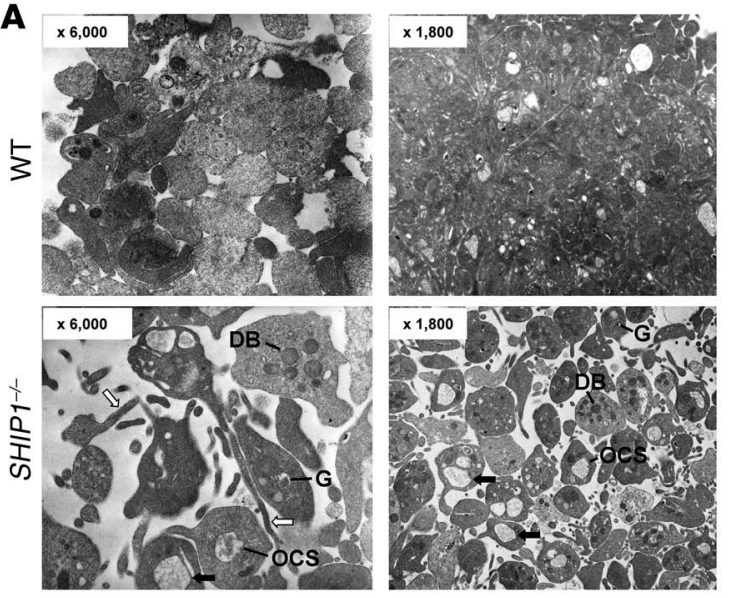

B
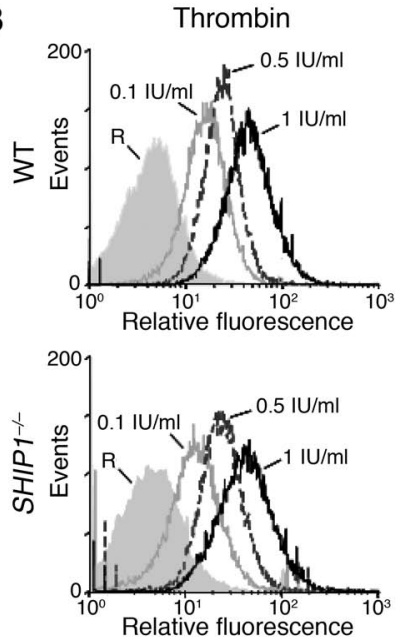

U46619
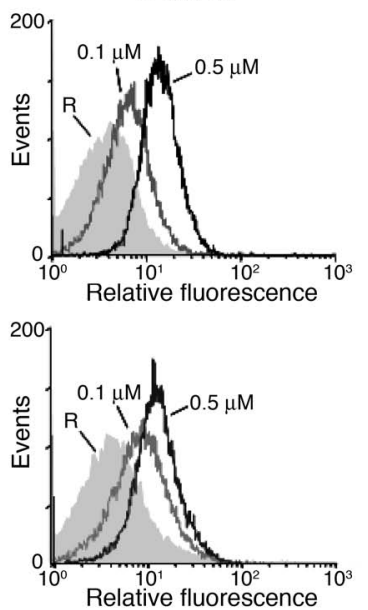

C
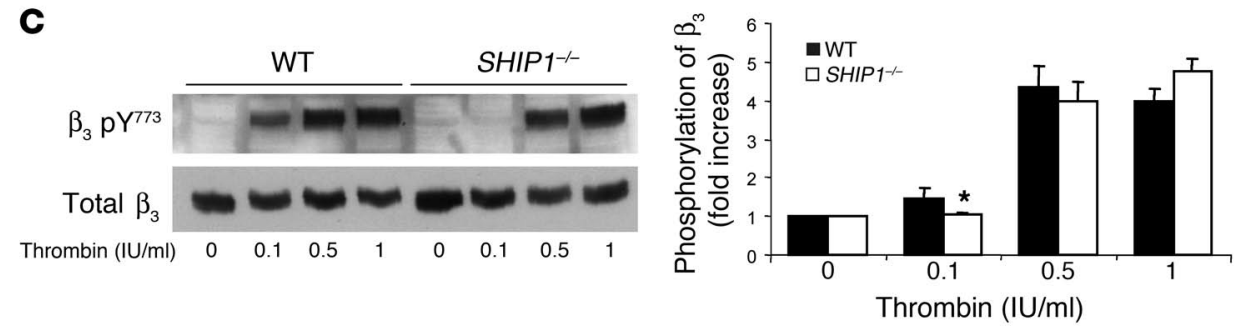

\section{Figure 4}

SHIP1-deficient platelets do not interact closely with each other upon stimulation despite normal fibrinogen binding. (A) Electron micrographs showing morphological features of WT and SHIP1-deficient platelets upon $1 \mathrm{lU} / \mathrm{ml}$ thrombin stimulation for 1 minute. Original magnification, $\times 6,000 ; \times 1800$. G, $\alpha$-granules; DB, dense bodies; OCS, open canalicular system. (B) The binding of labeled fibrinogen to WT and SHIP1-deficient mouse platelets activated by thrombin $(0.1$ to $1 \mathrm{IU} / \mathrm{ml})$ or $\mathrm{U} 46619(0.1 \mu \mathrm{M}$ and $0.5 \mu \mathrm{M})$ for 10 minutes was measured by flow cytometry. A representative example of 2 independent experiments is shown. R, resting. (C) WT and SHIP1-deficient mouse platelets were stimulated with increasing concentrations of thrombin $(0.1$ to $1 \mathrm{lU} / \mathrm{ml})$ for 3 minutes. The phosphorylation of the $\beta_{3}$ integrin cytoplasmic domain was assessed in resting and thrombin-stimulated platelets by immunoblotting with anti- $\beta_{3}$ integrin [pY ${ }^{773}$ phosphospecific antibody. A representative example of 4 independent experiments is shown. The phosphorylation level was estimated by densitometry analysis of Western blots, and the results are means \pm SEM $(n=4)$. *Significant difference $(P<0.05)$ versus WT, according to 1 -tailed Student's $t$ test.

(Figure 7A). The remaining transient peak of MLC phosphorylation at 10 seconds of stimulation is likely to be sufficient to support platelet-shape change, which appeared normal in response to the different agonists tested (Figure 1). Conversely, after a longer stimulation, corresponding to the formation of aggregates, MLC phosphorylation was fully inhibited in SHIP1-deficient platelets. Another method to evaluate contraction force is to measure fibrin clot retraction, which requires aggregation and firm membranecytoskeleton interactions. In the presence of thrombin $(2 \mathrm{IU} / \mathrm{ml})$ and atroxin, an $\mathrm{N}$-terminal fibrinopeptide $\mathrm{A}$-cleaving snake venom enzyme (19), WT platelets efficiently retracted the fibrin clot. Interestingly, SHIP1-deficient platelets were unable to induce fibrin clot retraction (Figure 7B). Overall, these results demonstrate the implication of SHIP1 in the platelet contractile apparatus.

\section{Discussion}

The hematopoietic phosphoinositide phosphatase SHIP1 is known to play important roles in the negative regulation of immune cells $(20,21)$. In platelets, this phosphatase plays a major role in the control of PtdIns $(3,4,5) \mathrm{P}_{3}$ and PtdIns $(3,4) \mathrm{P}_{2}$ levels upon stimulation (11). SHIP1-deficient platelets show a slight increase in basal PtdIns $(3,4,5) \mathrm{P}_{3}$ levels and dramatically accumulate this lipid in response to thrombin or collagen, whereas $\operatorname{PtdIns}(3,4) \mathrm{P}_{2}$ production is strongly impaired. In contrast to immune cells, normal platelets produce high amounts of $\operatorname{PtdIns}(3,4) \mathrm{P}_{2}$ during activation. This large accumulation of $\operatorname{PtdIns}(3,4) \mathrm{P}_{2}$, typical of platelets, is mainly dependent on the engagement of integrins and platelet aggregation $(22,23)$. The molecular targets and the functions of PtdIns $(3,4) \mathrm{P}_{2}$ are still poorly characterized. Several groups have shown that PI3K and Akt are involved in promoting and maintaining platelet aggregation $(1,2,24,25)$, but the relative contribution of PtdIns $(3,4) \mathrm{P}_{2}$ and PtdIns $(3,4,5) \mathrm{P}_{3}$ remains unknown. Here, we investigated whether SHIP1, a major regulator of the level of these 2 PI3K products, has a role in the regulation of platelet functions. Our results point to an important contribution of SHIP1 in the control of platelet aggregation and in hemostasis. Using in vitro approaches, we found a strong decrease in the amplitude of platelet aggregation in response to thrombin, U46619, and collagen. The size of the aggregates was dramatically reduced in the absence of SHIP1, but these small aggregates appeared stable. Accordingly, SHIP1-deficient platelets formed smaller thrombi than WT platelets in an in vitro thrombus formation assay under physiological flow conditions using whole blood perfused over a matrix of collagen. Again, these small thrombi were stable. 
A

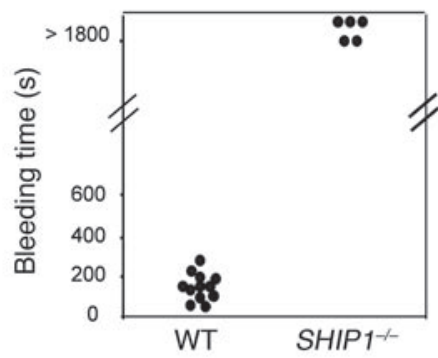

B Time (s) $\quad 8$

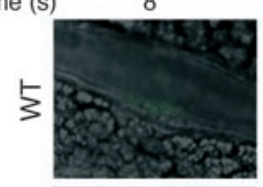

30
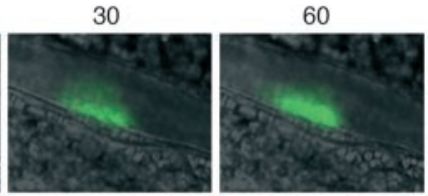

90
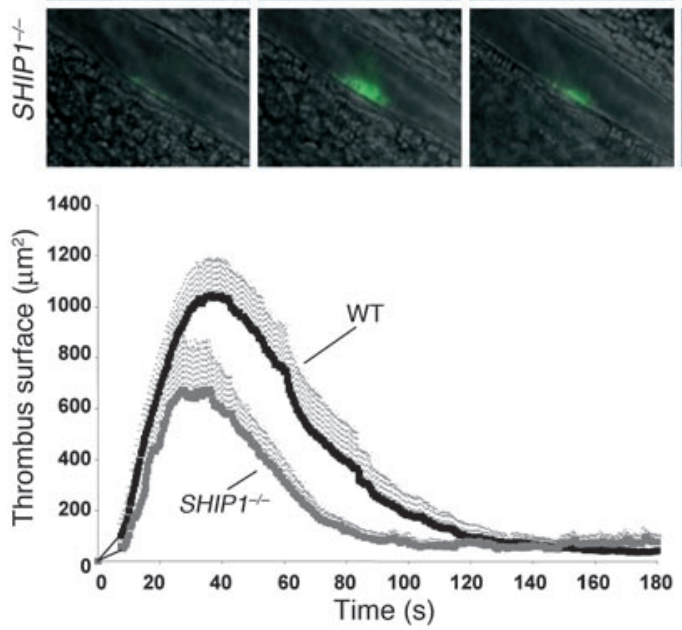

\section{Figure 5}

Impaired bleeding time and thrombus formation in SHIP1deficient mice. (A) The tail bleeding time of WT $(n=12)$ and SHIP1-deficient $(n=5)$ mice was measured as described in Methods. (B) Thrombus formation over time following laserinduced injury of mesenteric artery wall of WT and SHIP1-deficient mice was followed by intravital microscopy (objective, $\times 40$; scale bar: $20 \mu \mathrm{m}$ ). The mean thrombus surface was analyzed at 0.3-second intervals, and the shading over the curve represents the SEM at each time point in 6 WT mice $(n=22$ vessels) and 6 SHIP1-deficient mice ( $n=16$ vessels). Time 0 corresponds to the time of injury.

deficient platelets stimulated by thrombin. Furthermore, $\alpha_{\text {IIb }} \beta_{3}$ outside-in signaling leading to $\beta_{3}$ tyrosine phosphorylation was less efficient at low doses of agonist but appeared normal at high doses of thrombin, despite the formation of small aggregates.

Thrombus generation is a complex process requiring many regulatory components. Among them, cytosolic calcium is an important element. In agreement with Pasquet et al. (12), we found that agonist-induced PLC activation and calcium mobilization of SHIP1-deficient platelets, in suspension, were not significantly modified in the absence of external calcium. In the presence of external calcium, we and Maxwell et al. (13) found no difference in the basal cytosolic calcium level of SHIP1-deficient platelets, whereas Pasquet et al. (12) observed an increase in this level through a mechanism dependent on $\operatorname{PtdIns}(3,4,5) \mathrm{P}_{3}$ and Bruton's tyrosine kinase (Btk). This pathway, not identified in other hematopoietic cells, remains to be elucidated. Our results suggest that the aggregation defect of SHIP1-deficient platelets is not due to a major difference in calcium mobilization. Maxwell et al. (13) showed that there was no difference in the peak level of cytosolic calcium or the overall pattern of cytosolic calcium flux in SHIP1-deficient platelets adhered on fibrinogen; however, using real-time confocal microscopy they observed a more sustained oscillatory calcium response, even in the absence of external calcium. The authors propose that SHIP1 deficiency induced an accumulation of $\operatorname{PtdIns}(3,4,5) \mathrm{P}_{3}$ in response to $\alpha_{\mathrm{II}} \beta_{3}$ integrin engagement that could sustain PLC $\gamma$ activation and, in turn, calcium mobilization. In parallel, an increased spreading of SHIP1-deficient platelets on fibrinogen was observed (S. Séverin, unpublished observations; ref. 13), suggesting that this phosphatase could act as a negative regulator of $\alpha_{\text {II }} \beta_{3}$-mediated signaling (13).

However, when platelets are stimulated in suspension, SHIP1 may regulate early molecular processes as well as post-integrin engagement events. A possible explanation that might take into account the different observations is that SHIP1-deficient platelets have a defect in the contractile apparatus that could contribute to the increased spreading.

Electron microscopy analysis indicated that the ultrastructures of WT and SHIP1-deficient platelets are comparable under resting conditions. However, distension of the internal membrane system with appearance of large vacuoles, membrane extensions, and decreased cell-cell contacts was observed in SHIP1-deficient platelets in response to thrombin. It is noteworthy that a significant membrane surface of the OCS and likely a population of integrins remain accessible for soluble ligands but are not available for 
A

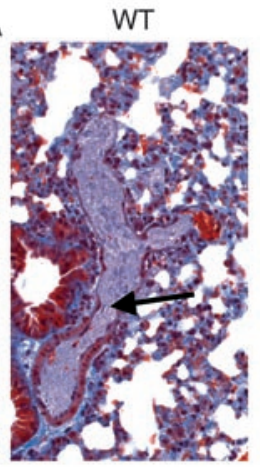

B

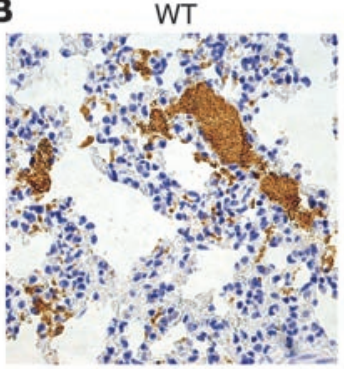

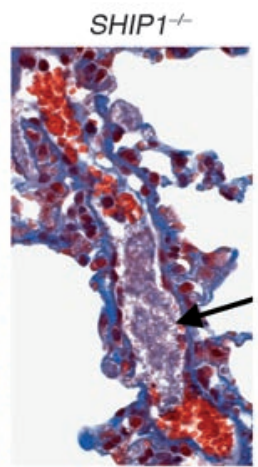

$\mathrm{SHIP}^{-1}$

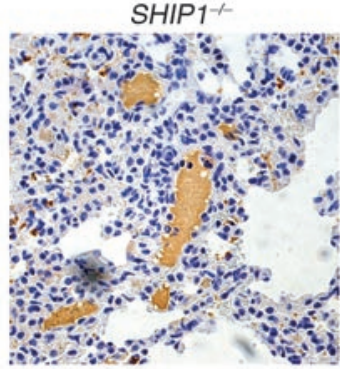

\section{Figure 6}

Histology and immunohistochemistry of WT and SHIP1-deficient mice injected with collagen and epinephrine. (A) Sections of lung tissue were stained with Masson trichrome. Arrows point to thrombi in the pulmonary vasculature of WT and SHIP1-deficient mice. Original magnification, $\times 200$. (B) Platelet staining (brown) revealing extensive platelet thromboemboli in WT mice and a decrease in platelet number in thrombi formed in SHIP1-deficient platelets. Original magnification, $\times 200$.

platelet-platelet interactions, probably contributing to the decrease in aggregation and thrombus growth. These morphological modifications strongly suggest that SHIP1 is required for contraction. This was confirmed by a strong decrease in the MLC phosphorylation in SHIP1-deficient platelets stimulated by thrombin. Accordingly, the loss of SHIP1 impaired the cellular retraction of the fibrin clot under conditions in which the $\beta_{3}$ integrin cytoplasmic domain was tyrosine-phosphorylated. These results strongly suggest that SHIP1 is involved in platelet actomyosin-mediated contraction. Preliminary results indicate that both the actin cytoskeleton reorganization and the microtubule dynamics are strongly affected by SHIP1 deficiency in response to thrombin. This lack of contractility may explain the fact that platelets are no longer able to establish close contacts with each other. There is an emerging concept that contact-dependent signaling $(26,27)$ may be very important to reach full platelet activation and, in turn, formation of large and well-structured aggregates to promote thrombus growth. The mechanical forces generated by MLC phosphorylation and actomyosin-dependent contractile activity are thought to compress the space between platelets, amplifying platelet secretion (28).

How can SHIP1 regulate platelet contractility? PI3K products have been suggested to contribute to the reorganization of the actin cytoskeleton, a critical process in the establishment of contractile forces. PtdIns $(3,4) \mathrm{P}_{2}$ can interact with the pleckstrin homology $(\mathrm{PH})$ domain of lamellipodin, a protein involved in the dynamics of the actin cytoskeleton (29). We have previously shown that inhibition of PtdIns $(3,4) \mathrm{P}_{2}$ production leads to a rapid detachment of myosin from the actin cytoskeleton (1). PtdIns $(3,4,5) \mathrm{P}_{3}$ can recruit

a number of $\mathrm{PH}$ domain-containing proteins, including Akt, Vav, PLC $\gamma 2$, and Tec tyrosine kinases, which are involved in platelet regulation processes. Thus, SHIP1 likely plays a critical temporal regulatory function by turning off $\operatorname{PtdIns}(3,4,5) \mathrm{P}_{3}$-dependent processes and switching on $\operatorname{PtdIns}(3,4) \mathrm{P}_{2}$-mediated signaling. It may also influence the formation of signaling complexes via its docking-protein properties. Its close homolog SHIP2 is known to interact with cytoskeletal elements such as filamin (30). Determination of the exact role of $\operatorname{PtdIns}(3,4) \mathrm{P}_{2}$ and of the importance of SHIP1 as a docking protein will be essential in understanding the molecular mechanisms deregulated in SHIP1-deficient platelets.

In contrast to the well-established role of SHIP1 in the negative regulation of lymphocytes, our study shows, for the first time to our knowledge, the essential role of this phosphoinositide 5 -phosphatase in the in vitro and in vivo platelet activation process. Interestingly, this phosphatase is essential for the formation of large aggregates with tightly associated platelets, leading to the formation of an efficient hemostatic plug growth and organization.

\section{Methods}

Materials. Collagen was from Nycomed, U46619 from QBiogene Inc., glass microcapillaries from ibidi, and FITC-labeled anti-P-selectin antibody from BD Biosciences - Pharmingen. 5-Hydroxy $\left[{ }^{14} \mathrm{C}\right]$ tryptamine $(56.0$ $\mathrm{mCi} / \mathrm{mmol}$ ) and SuperSignal West Pico Chemiluminescent Substrate were from Amersham International. $\mathrm{DiOC}_{6}$, Indo-1/AM, Pluronic F-127, and Oregon Green 488-conjugated fibrinogen were from Invitrogen. Anti- $\beta_{3}$ integrin $\left[\mathrm{pY}^{773}\right]$ phosphospecific antibody was from BioSource International Inc. Anti- $\beta_{3}$ integrin antibody and peroxidase-conjugated secondary antibodies were purchased from Cell Signaling Technology. Rabbit polyclonal anti- $\alpha_{\text {II }}$ integrin antibody and mouse monoclonal anti-phospho-MLC (Ser 19) antibody were from Santa Cruz Biotechnology Inc. SR-121566 was a gift from P. Savi (Sanofi Aventis, Toulouse, France). All other reagents were purchased from Sigma-Aldrich.

Animals. WT and mutant mice deficient in SHIP1, generated as previously described (14), were of C57BL/6 genetic background and housed in the Institut Fédératif de Recherche-Toulouse Purpan vivarium according to institutional guidelines. For all experiments, 5- to 10-week-old mice were used. Ethical approval for animal experiments was received from the French Ministry of Research in accordance with the European Union guidelines and had total committee approval.

Preparation of platelets and in vitro aggregation studies. Whole blood was drawn from the inferior vena cava of anesthetized mice into a syringe containing acid citrate dextrose ( $1 \mathrm{vol}$ anticoagulant/9 vol blood). To obtain an optimal amount of platelet-rich plasma (PRP), blood was mixed with 1 volume of modified HEPES-Tyrode's buffer ( $140 \mathrm{mM} \mathrm{NaCl}, 2 \mathrm{mM} \mathrm{KCl}, 12 \mathrm{mM}$ $\mathrm{NaHCO}_{3}, 0.3 \mathrm{mM} \mathrm{NaH}_{2} \mathrm{PO}_{4}, 1 \mathrm{mM} \mathrm{MgCl}$, $5.5 \mathrm{mM}$ glucose, 5 mM HEPES, $\mathrm{pH}$ 6.7) containing $2 \mathrm{mM}$ EGTA and $0.35 \%$ HSA. After centrifugation at $150 \mathrm{~g}$ for 2 minutes, PRP was removed and a further $300 \mu \mathrm{l}$ of modified HEPES-Tyrode's buffer was added to the remaining blood, which was then centrifuged at $150 \mathrm{~g}$ for 2 minutes. Then, $\mathrm{PGI}_{2}$ at a final concentration of $500 \mathrm{nM}$ was added to the PRP, and platelets were pelleted by centrifugation at $1,000 \mathrm{~g}$ for 4 minutes at $37^{\circ} \mathrm{C}$. Platelet pellets were finally resuspended in modified HEPES-Tyrode's buffer without EGTA ( $\mathrm{pH}$ 7.38), pooled at a density of $5 \times 10^{8}$ platelets per milliliter in the presence of $0.02 \mathrm{U} / \mathrm{ml}$ of the ADP scavenger apyrase (adenosine- $5^{\prime}$-triphosphate diphosphohydrolase), and incubated for 45 minutes at $37^{\circ} \mathrm{C}$ before platelet stimulation. Optical platelet aggregation experiments were monitored by a turbidimetric method using a dual-channel aggregometer (Payton Associates) with continuous stirring at $900 \mathrm{rpm}$ at $37^{\circ} \mathrm{C}\left(5 \times 10^{8}\right.$ platelets $\left./ \mathrm{ml}\right)$. Calcium measurements were as described in Supplemental Methods. 

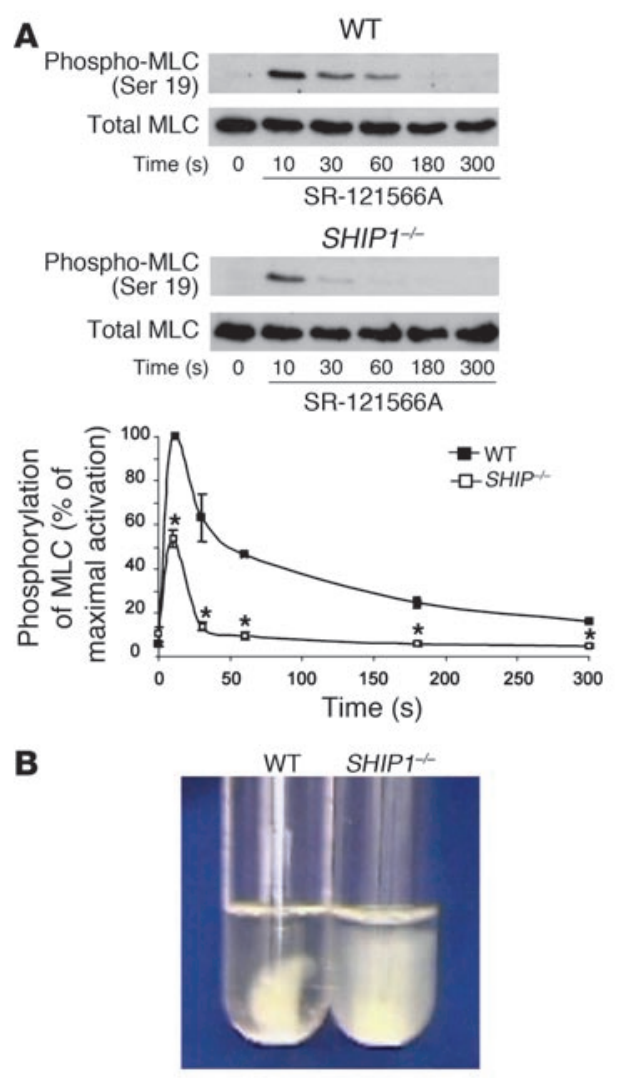

In vitro model of thrombosis on immobilized collagen under flow conditions. Glass microcapillaries were coated with $500 \mu \mathrm{g} / \mathrm{ml}$ type I collagen from equine tendon for 1 hour at $37^{\circ} \mathrm{C}$. The flow chamber, mounted on an epifluorescence microscope (Axiovert 200; Zeiss), allowed direct visualization of the platelet adhesion and aggregation process, which was recorded with a charge-coupled device camera (CoolSNAP HQ; Roper Scientific). Mouse blood was drawn into lepirudin $(200 \mathrm{IU} / \mathrm{ml})$, and DiOC $6(2 \mu \mathrm{M}$, 10 minutes at $37^{\circ} \mathrm{C}$ ) was used to label platelets in whole blood. Labeled blood was then perfused through collagen-coated glass microcapillaries for 2 minutes at a wall shear rate of $1,500 \mathrm{~s}^{-1}\left(15\right.$ dynes $\left./ \mathrm{cm}^{2}\right)$, followed by washing for 2 minutes at the same shear rate with PBS. Thrombus formation was visualized with a $\times 40$ long-working-distance objective in real time (acquisition rate: 1 frame every 5 seconds) for both fluorescent and transmitted light microscopy. Image sequences of the time-lapse recording and analysis of surface coverage were performed off-line on single frame using MetaMorph software (Universal Imaging Corp.). After deconvolution, a lower intensity threshold was applied to distinguish platelets from the background, a similar threshold was then used for analysis of all Z-stacks collected for a given experiment. Thrombus volume was calculated as the summation of partial volumes measured from the area occupied by platelets in each plane of $Z$-stacks.

Gel electrophoresis and immunoblotting. Proteins were resuspended in electrophoresis sample buffer containing $100 \mathrm{mM}$ Tris- $\mathrm{HCl}$ (pH 6.8), 15\% (vol/vol) glycerol, $25 \mathrm{mM} \mathrm{DTT}$, and 3\% SDS, boiled for 5 minutes, separated on SDSPAGE, transferred onto a nitrocellulose membrane (Gelman Sciences), and analyzed as previously described (31) using the relevant antibody.

Measurement of $\alpha$-granule and dense-granule secretion. To measure $\alpha$-granule secretion, washed platelets $\left(5 \times 10^{8}\right.$ platelets $\left./ \mathrm{ml}\right)$ were stimulated with indicated concentrations of thrombin, collagen, and the thromboxane $\mathrm{A}_{2}$ analogue $\mathrm{U} 46619$ at $37^{\circ} \mathrm{C}$ for 10 minutes without shaking. Platelets

\section{Figure 7}

Defects in MLC phosphorylation and fibrin clot retraction in SHIP1deficient platelets. (A) MLC phosphorylation was monitored by Western blotting with an anti-phospho-MLC (Ser 19) antibody. The phosphorylation level was estimated by densitometry analysis of Western blots, and the results are expressed as percentages of the maximum phosphorylation and are mean \pm SEM of 3 independent experiments. *Significant difference $(P<0.05)$ versus WT, according to 1-tailed Student's $t$ test. (B) Photographs show the extent of clot retraction in WT and SHIP1-deficient PRP samples treated with $2 \mathrm{IU} / \mathrm{ml}$ thrombin and $0.1 \mu \mathrm{g} / \mathrm{ml}$ atroxin. Results are representative of 2 independent experiments.

$\left(1 \times 10^{6}\right)$ were incubated with $1 \mu \mathrm{g} / \mu \mathrm{l}$ FITC-labeled anti-P-selectin antibody for 30 minutes in a final volume of $100 \mu \mathrm{l}$ at room temperature, then fixed with $1 \%$ formalin for 10 minutes and diluted 3 times in HEPESTyrode's buffer. Samples were analyzed with a FACScan flow cytometer (BD Biosciences) and CellQuest software (BD Biosciences). Dense-granule secretion was investigated by platelet 5 -hydroxy $\left[{ }^{14} \mathrm{C}\right]$ tryptamine release in response to different stimuli under stirring conditions, as described previously (15).

Electron microscopy. Washed platelets were activated with $1 \mathrm{IU} / \mathrm{ml}$ thrombin at $37^{\circ} \mathrm{C}$, fixed with a mixture of $2.5 \%$ paraformaldehyde and $2.5 \%$ glutaraldehyde in Sörensen's buffer $(0.1 \mathrm{M}, \mathrm{pH} 7.2)$, then postfixed with $1 \%$ osmium tetroxide in phosphate buffer, dehydrated, and embedded in eponaraldite resin. Ultrathin sections contrasted with uranyl acetate and lead citrate were examined with the use of a Hitachi H600 electron microscope or a JEOL JEM 2010 electron microscope for microdiffraction analysis.

Fibrinogen binding assays. Washed platelets $\left(1 \times 10^{8}\right.$ platelets $\left./ \mathrm{ml}\right)$ were incubated simultaneously with $0.5 \mathrm{IU} / \mathrm{ml}$ thrombin, Oregon Green 488 conjugated fibrinogen $(150 \mu \mathrm{g} / \mathrm{ml}$ in final volume), and Tyrode's buffer in a final volume of $100 \mu \mathrm{l}$. After 10 minutes at $37^{\circ} \mathrm{C}$ without shaking, samples were fixed by the addition of formalin ( $1 \%$ in final volume) and then diluted 5 times with HEPES-Tyrode's buffer. Samples were analyzed by flow cytometry using a FACScan and CellQuest software.

Tail bleeding time. We measured bleeding by $3-\mathrm{mm}$ tail-tip transection in mice anesthetized by an i.p. injection of a mixture of ketamine $(25 \mathrm{mg} / \mathrm{kg})$ and xylazine $(10 \mathrm{mg} / \mathrm{kg})$. A stopwatch was started immediately upon transection to determine the time required for the bleeding to stop. Blood drops were removed every 15 seconds with the use of a paper filter. If bleeding did not recur within 30 seconds of cessation, it was considered stopped. Experiments were terminated after 30 minutes if no cessation of blood flow occurred.

In vivo models of thrombosis. Mice weighing about $15 \mathrm{~g}$ and 3-5 weeks old were anesthetized, and their mesentery was exteriorized. An arteriole having a diameter of about $70 \mu \mathrm{m}$ was observed under an inverted Leica DM IRB microscope. Localized injury of the luminal surface of the vessel was induced with a pulsed nitrogen dye laser $(440 \mathrm{~nm})$ applied through the microscope objective $(\times 40)$ with a MicroPoint laser system (Photonic Instruments) as previously described $(32,33)$. Measure of thrombus surfaces was performed on platelets labeled with $\mathrm{DiOC}_{6}$. $\mathrm{DiOC}_{6}(0.5 \mu \mathrm{mol} / \mathrm{g}$ body weight) was injected into the jugular vein before vessel injury, and the fluorescence of platelets incorporated into the thrombi was visualized every 0.3 seconds. Thrombus formation was analyzed by wide-field and fluorescent light microscopy with a charge-coupled device CoolSNAP HQ camera (Roper Scientific) and SlideBook software (Intelligent Imaging Innovations).

The acute systemic vascular thromboembolism experiment, a mixture of collagen $(0.4 \mathrm{mg} / \mathrm{kg})$ and epinephrine $(60 \mu \mathrm{g} / \mathrm{kg})$ was injected into the right jugular vein of mice anesthetized by an i.p. injection of ketamine $(50 \mathrm{mg} / \mathrm{kg})$ and xylazine $(20 \mathrm{mg} / \mathrm{kg})$. 
Histochemical analysis of mouse lung. To visualize thrombi in the pulmonary vasculature, anesthetized mice were euthanized 3 minutes after injection of the collagen $(0.15 \mathrm{mg} / \mathrm{kg})$ and adrenaline $(60 \mu \mathrm{g} / \mathrm{kg}) \mathrm{mix}-$ ture, and their lungs were excised and formalin-fixed. Paraffin sections ( $5 \mu \mathrm{m}$ thick) were stained with Masson trichrome and then analyzed histologically for the presence of thrombi. Immunohistochemistry was performed on the paraffin-embedded lung sections as previously described (34). Platelets were identified with the use of a rabbit anti- $\alpha_{\text {IIb }}$ integrin antibody.

Clot retraction experiments. Clot retraction studies were performed as described previously (35). PRP was obtained from pooled blood samples from several mice by centrifugation for 4 minutes at $250 \mathrm{~g}$ at $37^{\circ} \mathrm{C}$. Platelets were then washed with modified HEPES-Tyrode's buffer ( $\mathrm{pH}$ 6.7) containing $2 \mathrm{mM}$ EGTA and $0.35 \% \mathrm{HSA}$, and resuspended $\left(3 \times 10^{8}\right.$ platelets/ $\mathrm{ml}$ ) without heparin in their autologous platelet-poor plasma containing $2 \mathrm{mM} \mathrm{MgCl}_{2}$ and $2 \mathrm{mM}$ EGTA. Thrombin and atroxin were added at a final concentration of $2 \mathrm{IU} / \mathrm{ml}$ and $0.1 \mu \mathrm{g} / \mathrm{ml}$, respectively, and the reaction mixtures were left unstirred at $37^{\circ} \mathrm{C}$.

Statistics. Statistical analyses were performed using Microsoft Excel 2003. $P$ values less than 0.05 were considered statistically significant.

\section{Acknowledgments}

This work was supported by grants from the Fondation de France (cardiovascular, contract no. 2003005647). S. Séverin was supported by grants from Groupe d'Etude sur l'Hémostase et la Thrombose and Nouvelle Société Française d'Athérosclérose. We wish to thank G. Chicanne, C. Racaud-Sultan, F. Gaits-Iacovoni, H. Tronchere, S. Manenti, P. Nurden, and A. Nurden for stimulating discussions; and the Plateforme d'Histopatologie Expérimentale of IFR 30 (T. Al Saati and F. Capilla) and the Flow Cytometry Core Facility of IFR 30 (F. L'Faqihi-Olive) for technical help. We thank S. Allart of the Imaging Core Facility of IFR 30 for her expert contribution to the flow-based studies.

Received for publication August 4, 2006, and accepted in revised form January 9, 2007.

Address correspondence to: Marie-Pierre Gratacap, INSERM U 563, CHU Purpan, BP 3028, 31024 Toulouse Cedex 03, France. Phone: 33 562-74-45-22; Fax: 33-562-74-45-58; E-mail: marie-pierre.gratacap@ toulouse.inserm.fr.
1. Trumel, C., et al. 1999. A key role of adenosine diphosphate in the irreversible platelet aggregation induced by the PAR1-activating peptide through the late activation of phosphoinositide 3-kinase. Blood. 94:4156-4165.

2. Kovacsovics, T.J., et al. 1995. Phosphoinositide 3-kinase inhibition spares actin assembly in activating platelets but reverses platelet aggregation. J. Biol. Chem. 270:11358-11366.

3. Jackson, S.P., et al. 2005. PI3K p110beta: a new target for antithrombotic therapy. Nat. Med. 11:507-514.

4. Oudit, G.Y., et al. 2004. The role of phosphoinositide- 3 kinase and PTEN in cardiovascular physiology and disease. J. Mol. Cell. Cardiol. 37:449-471.

5. Liu, Q., et al. 1999. SHIP is a negative regulator of growth factor receptor-mediated PKB/Akt activation and myeloid cell survival. Genes Dev. 13:786-791.

6. Taylor, V., et al. 2000. 5' phospholipid phosphatase SHIP-2 causes protein kinase B inactivation and cell cycle arrest in glioblastoma cells. Mol. Cell. Biol. 20:6860-6871.

7. Damen, J.E., et al. 1996. The 145 -kDa protein induced to associate with Shc by multiple cytokines is an inositol tetraphosphate and phosphatidylinositol 3,4,5-triphosphate 5-phosphatase. Proc. Natl. Acad. Sci. U. S. A. 93:1689-1693.

8. Helgason, C.D., et al. 1998. Targeted disruption of SHIP leads to hemopoietic perturbations, lung pathology, and a shortened life span. Genes Dev. 12:1610-1620.

9. Moody, J.L., Xu, L., Helgason, C.D., and Jirik, F.R. 2004. Anemia, thrombocytopenia, leukocytosis, extramedullary hematopoiesis, and impaired progenitor function in $\mathrm{Pten}^{+/-} \mathrm{SHIP}^{-/-}$mice: a novel model of myelodysplasia. Blood. 103:4503-4510.

10. Giuriato, S., et al. 2000. pp60c-src associates with the SH2-containing inositol-5-phosphatase SHIP1 and is involved in its tyrosine phosphorylation downstream of alphaIIbbeta3 integrin in human platelets. Biochem. J. 348:107-112.

11. Giuriato, S., et al. 2003. SH2-containing inositol 5-phosphatases 1 and 2 in blood platelets: their interactions and roles in the control of phosphatidylinositol 3,4,5-trisphosphate levels. Biochem. J. 376:199-207.
12. Pasquet, J.M., et al. 2000. Phosphatidylinositol 3,4,5-trisphosphate regulates $\mathrm{Ca}(2+)$ entry via btk in platelets and megakaryocytes without increasing phospholipase C activity. EMBO J. 19:2793-2802.

13. Maxwell, M.J., et al. 2004. SHIP1 and Lyn kinase negatively regulate integrin alpha IIb beta 3 signaling in platelets. J. Biol. Chem. 279:32196-32204.

14. Liu, Q., et al. 1999. SHIP is a negative regulator of growth factor receptor-mediated $\mathrm{PKB} /$ Akt activation and myeloid cell survival. Genes Dev. 13:786-791.

15. Gratacap, M.P., et al. 1998. Phosphatidylinositol 3,4,5-trisphosphate-dependent stimulation of phospholipase C-gamma2 is an early key event in FcgammaRIIA-mediated activation of human platelets. J. Biol. Chem. 273:24314-24321.

16. Law, D.A., Nannizzi-Alaimo, L., and Phillips, D.R. 1996. Outside-in integrin signal transduction. Alpha IIb beta 3-(GP IIb IIIa) tyrosine phosphorylation induced by platelet aggregation. J. Biol. Chem. 271:10811-10815.

17. Furie, B., and Furie, B.C. 2005. Thrombus formation in vivo. J. Clin. Invest. 115:3355-3362. doi:10.1172/JCI26987.

18. Herault, J.P., Peyrou, V., Savi, P., Bernat, A., and Herbert, J.M. 1998. Effect of SR121566A, a potent GP IIb-IIIa antagonist on platelet-mediated thrombin generation in vitro and in vivo. Thromb. Haemost. 79:383-388.

19. Meh, D.A., Siebenlist, K.R., Bergtrom, G., and Mosesson, M.W. 1995. Sequence of release of fibrinopeptide A from fibrinogen molecules by thrombin or Atroxin. J. Lab. Clin. Med. 125:384-391.

20. Marshall, A.J., Niiro, H., Yun, T.J., and Clark, E.A 2000. Regulation of B-cell activation and differentiation by the phosphatidylinositol 3-kinase and phospholipase C gamma pathway. Immunol. Rev. 176:30-46.

21. Krystal, G. 2000. Lipid phosphatases in the immune system. Semin. Immunol. 12:397-403.

22. Kucera, G.L., and Rittenhouse, S.E. 1990. Human platelets form 3-phosphorylated phosphoinositides in response to $\alpha$-thrombin, U46619, or GTPS. J. Biol. Chem. 265:5345-5348.

23. Sultan, C., et al. 1991. Involvement of platelet glycoprotein IIb-IIIa $\left(\alpha_{\mathrm{IIb}}-\beta_{3}\right.$ integrin) in throm- bin-induced synthesis of phosphatidylinositol 3',4'-bisphosphate. J. Biol. Chem. 266:23554-23557.

24. Chen, J., et al. 2004. Impaired platelet responses to thrombin and collagen in AKT-1-deficient mice. Blood. 104:1703-1710.

25. Woulfe, D., et al. 2004. Defects in secretion, aggregation, and thrombus formation in platelets from mice lacking Akt2. J. Clin. Invest. 113:441-450. doi:10.1172/JCI200420267.

26. Prevost, N., et al. 2005. Eph kinases and ephrins support thrombus growth and stability by regulating integrin outside-in signaling in platelets. Proc. Natl. Acad. Sci. U. S. A. 102:9820-9825.

27. Brass, L.F., Zhu, L., and Stalker, T.J. 2005. Minding the gaps to promote thrombus growth and stability.J. Clin. Invest. 115:3385-3392. doi:10.1172/ JCI26869.

28. Flaumenhaft, R., et al. 2005. The actin cytoskeleton differentially regulates platelet alpha-granule and dense-granule secretion. Blood. 105:3879-3887.

29. Krause, M., et al. 2004. Lamellipodin, an Ena/VASP ligand, is implicated in the regulation of lamellipodial dynamics. Dev. Cell. 7:571-583.

30. Dyson, J.M., et al. 2003. SHIP-2 forms a tetrameric complex with filamin, actin, and GPIb-IX-V: localization of SHIP-2 to the activated platelet actin cytoskeleton. Blood. 102:940-948.

31. Gratacap, M.P., et al. 2000. FcgammaRIIA requires a Gi-dependent pathway for an efficient stimulation of phosphoinositide 3-kinase, calcium mobilization, and platelet aggregation. Blood. 96:3439-3446.

32. Falati, S., Gross, P., Merrill-Skoloff, G., Furie, B.C., and Furie, B. 2002. Real-time in vivo imaging of platelets, tissue factor and fibrin during arterial thrombus formation in the mouse. Nat. Med. 8:1175-1781.

33. Hechler, B., et al. 2003. A role of the fast ATP-gated $\mathrm{P} 2 \mathrm{X} 1$ cation channel in thrombosis of small arteries in vivo. J. Exp. Med. 198:661-667.

34. Smyth, S.S., Reis, E.D., Vaananen, H., Zhang, W., and Coller, B.S. 2001. Variable protection of beta 3 -integrin-deficient mice from thrombosis initiated by different mechanisms. Blood. 98:1055-1062.

35. Bodin, S., et al. 2005. Integrin-dependent interaction of lipid rafts with the actin cytoskeleton in activated human platelets. J. Cell Sci. 118:759-769. 